\title{
7 \\ Bioenergetic Habitat Modeling and Food Delivery for Drift Feeding Fishes in Streams
}

\section{Nicole S. Weber, Howard S. Wheater, Douglas J. Booker, Michael J. Dunbar and Anton T. Ibbotson}

Environmental and ecological impacts must be considered when designing any engineering works. In rivers, streams and other aquatic systems, this, in part, means identifying changes to physical and chemical parameters affecting habitats of the aquatic community. Due to Provincial and Federal legislation, fish habitat is typically isolated as the key indicator of aquatic impacts as a consequence of instream works. Understanding where fish locate themselves, and why, makes evaluating the impacts and restoration of streams more efficient and effective. One way to predict where fish habitat is optimal is to identify locations in the stream where energetic costs are low and energetic benefits (food) are high for a given fish type. This bioenergetic approach to modeling provides a physically-based quantification of the total amount and quality of fish habitat available under different flow conditions and stream configurations.

For drift feeding fishes, such as salmon or trout (important fisheries), inputs to this type of model include stream velocities (from hydraulic models) and the number of invertebrates drifting in the water column within range of the fish location. Previous field investigations have shown that the number of invertebrates drifting is heterogeneous over space and time. In numerical modeling discussed in this chapter, invertebrate start position and

Weber, N.S., H.S. Wheater, D.J. Booker, M.J. Dunbar and A.T. Ibbotson. 2007. "Bioenergetic Habitat Modeling and Food Delivery for Drift Feeding Fishes in Streams." Journal of Water Management Modeling R227-07. doi: 10.14796/JWMM.R227-07.

(C) CHI 2007 www.chijournal.org ISSN: 2292-6062 (Formerly in Contemporary Modeling of Urban Water Systems. ISBN: 0-9736716-3-7) 
behaviour can change the velocities experienced, and thereby substantially alter the invertebrate travel path in the water column. This may have an impact on fish habitat suitability if invertebrate densities on the stream bed are patchy or if invertebrate behaviours vary daily and/or seasonally. With more information on spatial food availability in the form of invertebrate drift dynamics, physically-based bioenergetic approaches could offer great improvements over conventional fish habitat models for streams.

\subsection{Introduction}

All engineering works require an assessment of the impact of the works on the natural environment. This often includes both potential chemical pollutants and physical changes to the environment. The impact of physical changes often comes in the form of estimated habitat loss to key species or groups of species. When working in or near aquatic environments, this usually means important endangered or commercial fish species. For example, in Canada, the Department of Fisheries and Oceans (DFO) has mandated that there be no net loss of fish habitat during any work (the construction of a structure or realignment of a stream for example), in or near aquatic environments (DFO, 1986).

The quantity and quality of habitat must be evaluated prior to work commencing and predicted for the completed state. This requires expert knowledge and potentially costly field analyses. Over the past fifteen years, techniques have been developed to model fish habitat using numerical techniques (Stalnaker et al., 1995; Bovee et al., 1998; Addley, 1993; Guensch, 2001; Booker et al., 2004). These models need the same initial effort to estimate existing fish habitat but can be used to predict fish habitat available under many possible physical conditions once that work has been done. In this way, the design of any development (flow regime change downstream of a dam, water abstraction plans or river realignment) can be optimized to ensure the best possible outcome for fish as well as those proposing the changes.

This chapter discusses the assumptions used in two types of fish habitat models: preference models, where habitat is estimated based on physical attributes of locations where fish have been observed, and bioenergetic models, where habitat is quantified based on the amount of energy available to fish in a given location. The chapter then goes on to explore the assumption of uniform food delivery to fish in drift feeding bioenergetic 
models and its potential impact on the accuracy of such models through the simulation of invertebrate drift in a lowland chalk stream (Bere Stream, Dorset, UK).

\subsection{Background}

\subsubsection{Fish Habitat Modeling in Streams}

Fish habitat models estimate the quantity and quality of habitat available to fish in a stream or river. In general, there are two types of model used for quantifying habitat in streams: preference models and bioenergetic models.

\section{Preference models}

Preference models predict the amount of habitat available under a set of physical conditions based on the physical conditions in locations where fish have been previously observed (Stalnaker et al., 1995; Bovee et al., 1998). The process of developing a model of this type is generally species and location specific. Observations are made on where fish are located in the stream of interest and/or similar streams nearby. The data collected are used to construct suitability indices for a range of parameters that often include depth, velocity, substrate size and cover.

Hydraulic model results of the stream are used to predict these parameters under existing and proposed conditions and a suitability value is assigned to areas based on the indices associated with the parameter values. The index values are weighted based on known preference and combined giving a weighted usable area map for the modeled stream reach. The process is shown schematically in Figure 7.1

Under many circumstances, preference models make two major assumptions that may lead to inaccuracy of results:

1. The entire basis of these models revolves around the observation of fish, assuming that they are situated in the best possible location. In reality, there are several things that may prevent a fish from being in an optimum location, including competition, predation avoidance and the absence of ideal circumstances.

2. Suitability indices are often developed in one area or situation and then used in, or transferred to, a situation 
where they may not, or may no longer, be relevant. Very

few studies have tested the transferability of suitability indices across geographic regions or other circumstances.

Further to these assumptions, preference-based habitat models give little information as to why a fish might be where it is (i.e. what the benefits are of being at one depth rather than another). All of these issues and the increase in computational power over the past decade led to the development and use of bioenergetic models for fish in streams, which try to avoid these pitfalls.

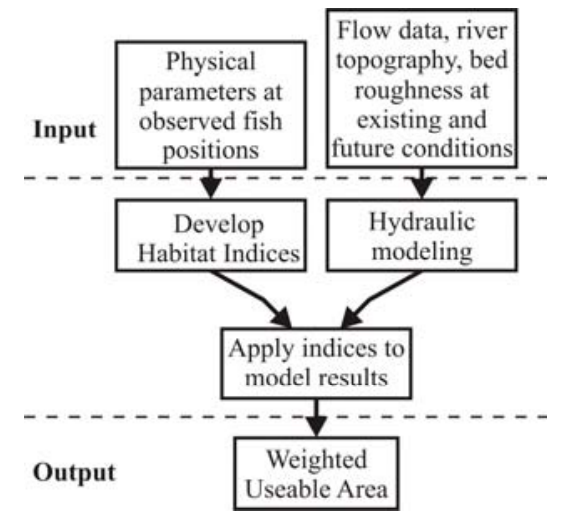

Figure 7.1 General preference habitat model schematic for organisms in rivers and streams

\section{Bioenergetic models}

Bioenergetic models balance the energy inputs and energy uses of an organism. The general principle is that energy consumed by the organism as food will be used for metabolism, movement or will be excreted. Any remaining energy (net energy intake (NEI)) may be used for growth and reproduction. The basic premise for using this technique for habitat modeling is to determine the NEI at locations an organism might occupy and for behaviours it exhibits there. In this way, it is possible to quantify the amount of good quality habitat (with high NEI) and low quality habitat (with low NEI) over an area or range of available behaviours.

Bioenergetic models have been developed for fish in a variety of locations and for many purposes (Jobling, 1994). In particular, these models have been produced for drift feeding fish in streams by several researchers 
(Hughes \& Dill, 1990; Hill \& Grossman, 1993; Addley, 1993; Hayes, 1996; Hayes et al., 2000; Guensch, 2001; Ibbotson et al., 2001; Booker et al., 2004; Rosenfeld et al., 2005). The basic equation that represents this process is given by:

$$
N E I=G E I-C o s t s
$$

where:

$$
\begin{aligned}
N E I= & \text { the Net Energy Intake, } \\
G E I= & \text { Gross Energy Intake, and } \\
\text { Costs }= & \text { the energetic costs associated with holding position } \\
& \text { in the stream, capturing food, digestion, and losses } \\
& \text { to urine and faeces. }
\end{aligned}
$$

GEI is based on estimated food intake for a fish at a specific location. All costs can be accounted for knowing the fish size, water velocity at a specific location and water temperature from known relationships and experiments with fish. The NEI at locations where velocity is known can be calculated for a range of fish sizes with temperatures and food densities estimated based on the time of year. When velocities are simulated using a 3D hydraulic model, NEI can be estimated throughout the velocity field of the modeled reach.

The above models include mean invertebrate drift density (number of invertebrates per unit volume of water) as an input. The density and composition of this drift affects energy inputs to the bioenergetic models. The model used by Addley (1993) and modified by Guensch (2001) and Booker et al. (2004) incorporates the size composition of the drift but uses a single drift density value for all locations in the stream for each size class. A sensitivity analysis provided by Addley (1993) shows that a $10 \%$ increase or decrease in the value of drift density in a stream can have a $8-9 \%$ increase or decrease respectively on the NEI value calculated, with all other inputs remaining the same. Similarly, Rosenfeld et al. (2005) showed that increasing drift density in experimental channels increased the velocities where fish were located and increased their growth rates even at these higher swimming speeds.

This has strong implications for the necessity of accurate drift density estimation in the determination of the quantity and quality of fish habitat in streams and rivers because the amount and location of useable habitat is dependent on the drift density. Although all these models use a single input of mean drift density, drift has been shown to be heterogeneous over space and time (Section 7.2.3). The ability to model the spatial heterogeneity of drifting invertebrates could lead to more accurate prediction of fish position 
and growth with bioenergetic models. With bioenergetic models sensitive to the drift density, knowing the drift density at different points in a stream reach could change the absolute and relative predicted NEI values compared with a single drift density value.

\subsubsection{Bioenergetic Fish Habitat Modeling: A Case Study on the Bere Stream (Southern England)}

A bioenergetic fish habitat model for juvenile Atlantic salmon and brown trout was developed for a lowland chalk stream in Southern England (Bere Stream, County Dorset). A full description of the site, model development, verification and testing is provided in Booker (2004). Figure 7.2 shows the schematic of how habitat in the form of NEI output is obtained based on measured values and numerical modeling.

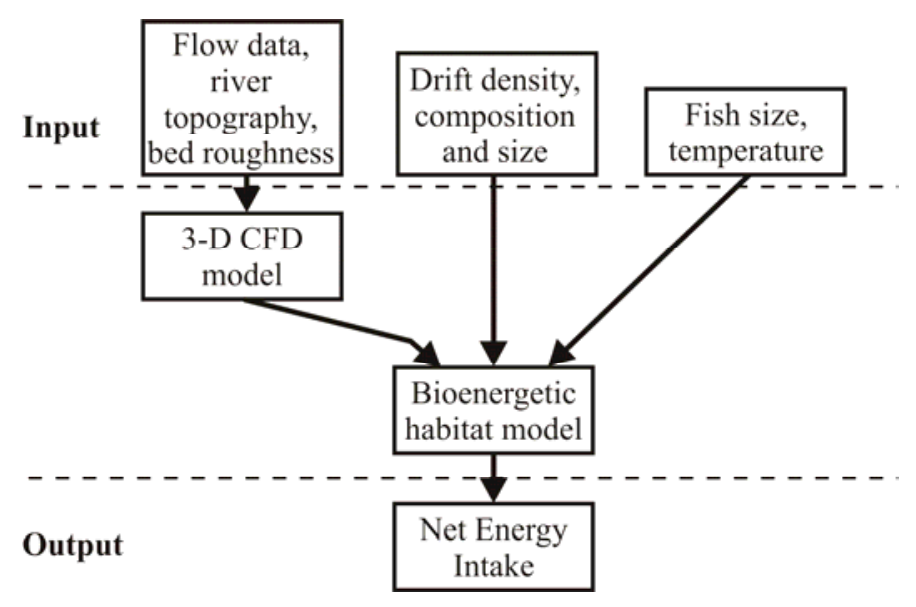

Figure 7.2 Current bioenergetic model schematic.

When the bioenergetic model was used to calculate NEI in the Bere Stream, it was compared to measured fish locations and behaviours. The model predicted high NEI values at $80 \%$ of fish locations. Of the fish located in areas with less than ideal NEI, many were not feeding and/or under cover of overhanging vegetation or instream debris. 


\subsubsection{Food Delivery for Drift Feeding Fishes}

The drift feeding fish featured in the Bere Stream bioenergetic model (brown trout and Atlantic salmon) get approximately $80 \%$ of their food from invertebrates drifting downstream in the water column. For the most part, these invertebrates originate on the stream bed. They leave the bed either due to shear forces dislodging them or due to a behavioural release. Invertebrates with aquatic stages in moving water have adapted to life with constant shear stresses and, except for catastrophic circumstances of high flows, or happenstance a bad foot hold, entry in to the drift is behavioural (Wilzbach et al., 1988). Many explanations have been given for why drifting may be of benefit to stream invertebrates: avoidance of benthic predators, avoidance of competition for food, and the search for better food sources are a few (see a review in Brittain, 1988).

As mentioned in Section 7.2.1, invertebrate drift is input as a single value for an entire stream reach in bioenergetic fish habitat models for drift feeding fish. However, several studies have shown that drift is not spatially homogeneous (Matter and Hopwood, 1980; Neale, 1999; Fenoglio et al., 2004). It is unclear how this variability in drift magnitude within a stream reach might affect fish positioning, so a model was developed to examine what factors might affect the spatial heterogeneity of invertebrate drift.

\subsubsection{Modeling Invertebrate Drift}

The individual nature, large size and low concentrations of invertebrates makes advection-diffusion models, commonly used in water quality and sediment modeling, inappropriate for invertebrate drift. Particle tracking, which models individuals separately, provides an ideal solution. These models have been used successfully for modeling other individual biological entities such as plankton (Eckman, 1990) and fish (Goodwin et al., 2001). Further, particle tracking gives a more adaptable platform to work within, where behaviours and/or preferences can be added to the basic model.

Basic particle tracking model is as follows:

$$
\begin{aligned}
& x_{i+1}=x_{i}+u_{i} \Delta t \\
& y_{i+1}=y_{i}+v_{i} \Delta t \\
& z_{i+1}=z_{i}+w_{i} \Delta t
\end{aligned}
$$

where: 


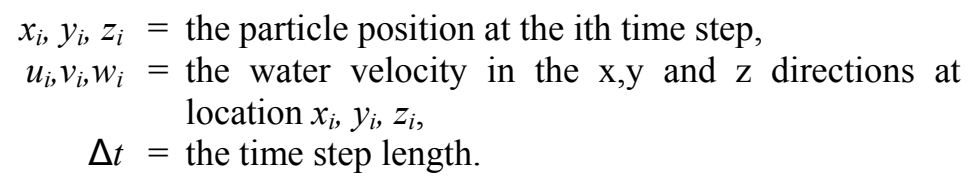

A full description and details of model testing are available (Weber, 2006).

To simulate the movement of invertebrates, preferences (in the form of directional movement toward a desired condition), swimming or other movement can be added to the basic model. For example, if a vertical swimming behaviour is simulated, the final line of Equation 7.1 becomes

$$
z_{i+1}=z_{i}+\left(w+w_{i n v}\right) \Delta t
$$

where:

$$
\begin{aligned}
\mathrm{z}_{i} & =\text { the vertical particle position at the ith time step, } \\
w_{i} & =\text { the vertical water velocity } \\
w_{i n v} & =\text { the invertebrate vertical velocity, and } \\
\Delta t & =\text { the time step }
\end{aligned}
$$

Three-dimensional hydraulic modeling of a stream reach gives velocities throughout the modeled reach. Interpolating the velocities at a particle position allows it to be tracked through the bounds of the reach.

\subsection{Sensitivity Analysis Methodology}

Using the invertebrate particle tracking model described (Section 7.2.4), several simulations were performed to explore how changes in the initial starting location and potential behaviours affect the drift path of an invertebrate and, in turn, the energy available to a fish within the stream reach.

\subsubsection{Test 1: Initial Particle Location}

Two hundred and fifty (250) particles, simulating Gammarus (freshwater shrimp), Simulids (black fly larvae) and Baetids (mayfly nymphs) were initiated on the bed in two distinct patterns; random and concentrated on locally shallow areas. In each case, the model was run under conditions 
observed on 1 May 2002 where the stream discharge was $0.73 \mathrm{~m}^{3} \mathrm{~s}^{-1}$ and the overall drift density was $5.2 \mathrm{~m}^{-3}$. The proportion of each type and size of invertebrate in the simulation was also determined by the May 1, 2002 samples. The model was run with a $0.1 \mathrm{~s}$ time step over $45 \mathrm{~s}$.

Invertebrates initiated their drift $0.02 \mathrm{~m}$ above the bed simulating a small jump or tumble. The model then tracked them through the water using Equations 7.1 and 7.2. The magnitudes of swimming velocities are dependent on the size and type of invertebrate simulated and are based on published values (Fonseca, 1999; Campbell, 1985; Weber, 2006). The invertebrates were simulated to swim to the surface and then swim down to the bed. Invertebrates were removed from the simulation when they either returned to the bed or reached the downstream end of the modeled reach.

\subsubsection{Test 2: Behaviour}

Two hundred and seventy (270) particles simulating a range of sizes of freshwater shrimp, mayfly nymphs and blackfly larvae initiated drift at 10 locations within the modeled reach as shown in Figure 7.3. As in Test 1, simulated invertebrates began at $0.02 \mathrm{~m}$ above the bed and, in this test, were assigned one of four vertical behaviours described in Table 7.1. The initial behaviour begins upon initiation and, given an upward initial behaviour, the secondary behaviour begins once the simulated invertebrates reach the water surface. Passive behaviour represents mean downward velocities of dead invertebrates in field and lab studies, whereas swimming behaviours represent a mean velocity shown by live invertebrates (Fonseca, 1999; Campbell, 1985; Weber, 2006). The hydraulic conditions observed on May 1, 2002 were used for the simulation (discharge of $0.73 \mathrm{~m} \mathrm{~s}^{3} \mathrm{~s}^{-1}$ ). The simulation was complete when all invertebrates returned to the bed/banks or left the simulation through the downstream boundary.

Table 7.1 Simulated behaviours.

\begin{tabular}{cll}
\hline Behaviour & Initial Behaviour & Secondary Behaviour \\
\hline 1 & Passive Down & - \\
2 & Swim Down & - \\
3 & Swim Up & Passive Down \\
4 & Swim Up & Swim Down \\
\hline
\end{tabular}




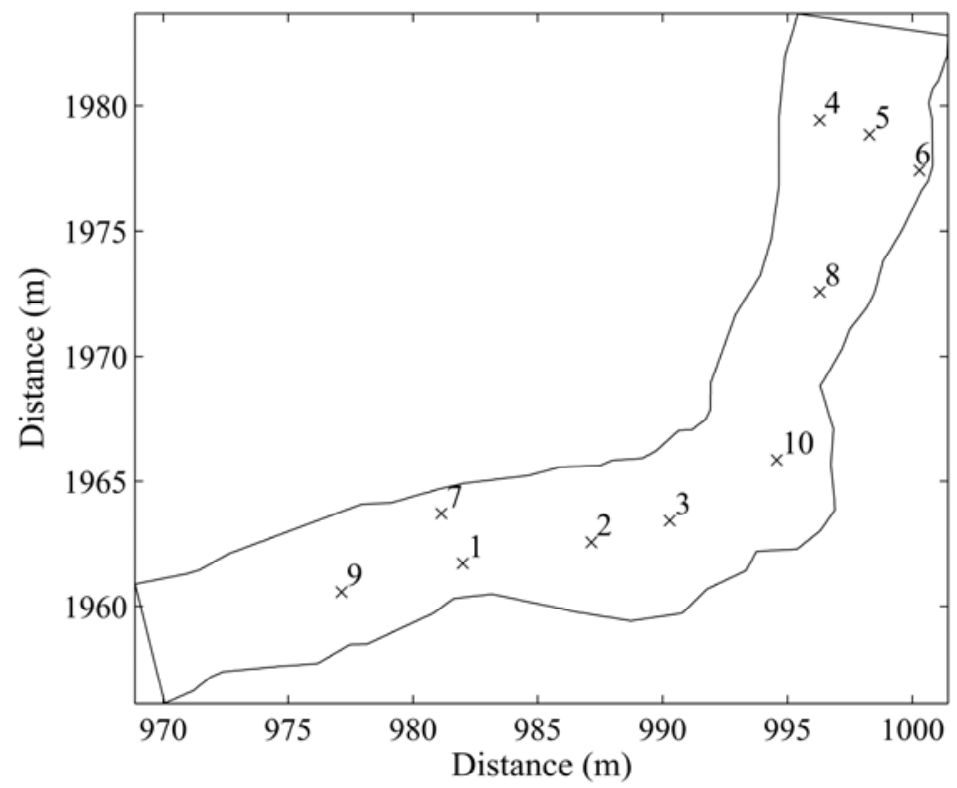

Figure 7.3 Locations of particle initiation for test of behaviour on invertebrate drift model results. Water flow is from top-right to bottomleft.

\subsection{Results}

\subsubsection{Test 1: Initial Particle Location}

The mean distance traveled by the particles was $4.5 \mathrm{~m}$ in the random source case, and $5.2 \mathrm{~m}$ in the shallow source case. These were not significantly different $(\mathrm{p}>0.05)$. The limitations of the time span of the simulations are notable with some particles never reaching their final destinations on the stream bed and several leaving the simulation through the downstream boundary. However, even with these complications, some interesting patterns can be observed.

Figures 7.4 and 7.5 show the paths of the particles in the random and shallow source simulations respectively. Areas of high path densities indicate areas of high concentrations of particles over the 45 second simulation. In both cases there is a concentration of particle paths at the 
inside of the bend. In Figure 7.4 (random source locations) further areas of high path density occur surrounding the shallowest areas (shown by cross stream lines in Figure 7.5). The particle paths tend to surround locations in the centre of the upstream shallow area, in the centre of the second shallow area and on the right bank of the downstream shallow area.

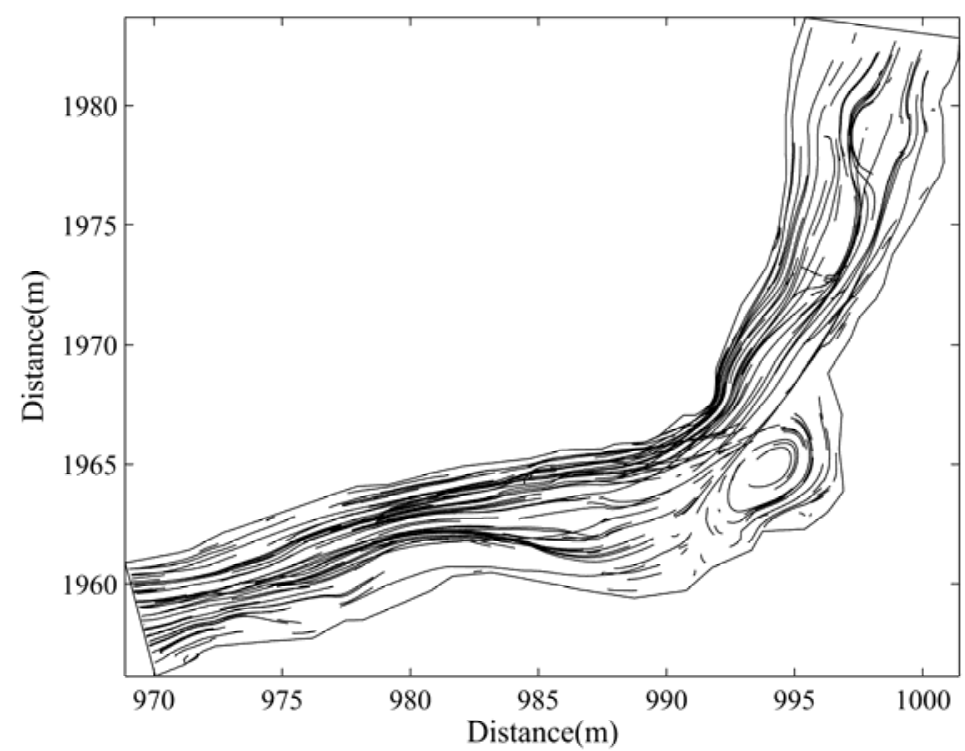

Figure 7.4 Drift paths of 250 simulated invertebrate particles with random initial distribution on the stream bed. Water flow is from topright to bottom-left.

Due to the concentration of particle source locations in the shallow source case, the same patterns are not seen. Particles initiate more commonly on or near the shallowest areas and, therefore, more paths pass over them. However, there do seem to be locations within the shallow areas, upstream of the shallowest locations where particles travel short distances (right bank of upstream area and centre of middle section).

One further observation is the pattern of particle paths within the pool on the outside of the bend. This pool is more than $1 \mathrm{~m}$ deep and has a recirculating flow pattern. In both cases shown, no particles that began in the pool left the pool and very few particles that began outside of the pool entered the recirculation pattern. In the shallow source case, no simulated invertebrates entered the deep pool. 


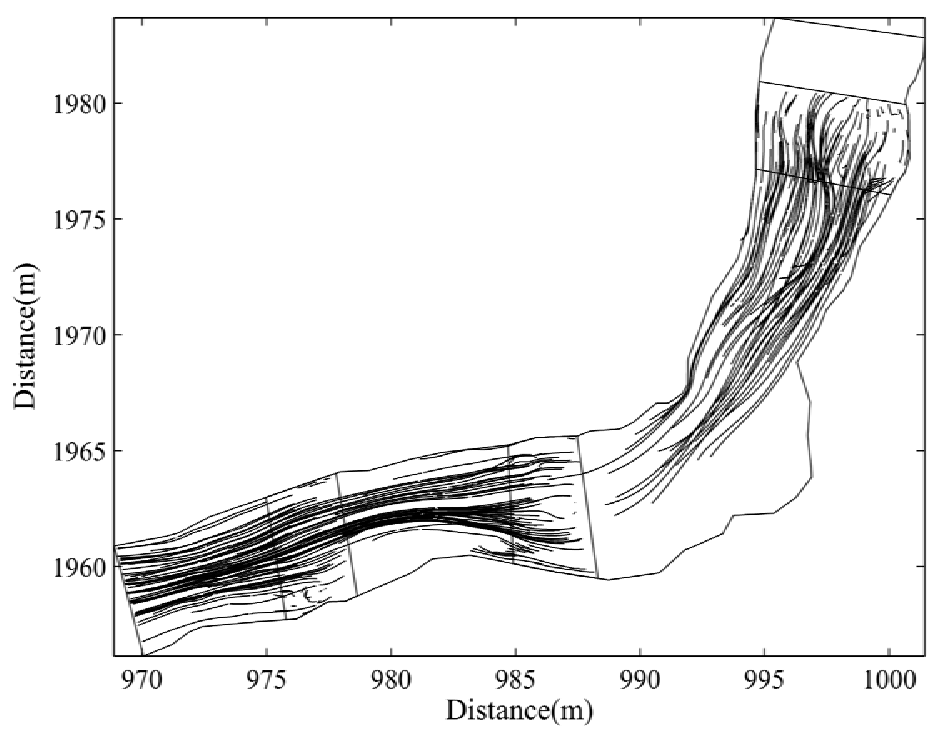

Figure 7.5 Drift paths of 250 simulated invertebrate particles with an initial distribution on the stream within shallow areas. Water flow is from top-right to bottom-left. The lines across the stream indicate the boundaries for initial positions.

\subsubsection{Test 2: Behaviour}

In the simulations of the first two behaviours (no upward swimming) the particles have more similar cumulative distances traveled and overall times spent in the drift than when they are compared to Behaviours 3 and 4, where upward swimming occurs. Table 7.2 shows the mean and standard deviation of the distance traveled, the overall time spent in the drift and the number of particles leaving through the downstream end for each behaviour.

Figures 7.6 and 7.7 show the particle paths for the four behaviours in the horizontal and vertical directions for two particles. Note that the initial upward swimming stage of Behaviours 3 and 4 are the same and the lines overlap exactly on the plots. Often, particle paths for Behaviours 1 and 2 end much more quickly than those for Behaviours 3 and 4 and are not seen well on these path plots. The solid grey lines on the plots of horizontal position represent extents of the modeled stream. 
Table 11.2 The mean ( \pm standard deviation) of the distance traveled, and time spent drifting and the number of particles leaving the downstream boundary for each behaviour simulated.

\begin{tabular}{cllll}
\hline Behaviour & 1 & 2 & 3 & 4 \\
\hline Distance Traveled (m) & $1.52 \pm 2.83$ & $1.26 \pm 2.64$ & $10.8 \pm 7.62$ & $8.71 \pm 7.42$ \\
Drift Duration (s) & $5.74 \pm 10.4$ & $4.99 \pm 13.7$ & $47.3 \pm 42.4$ & $40.8 \pm 47.4$ \\
Number through Downstream & 5 & 7 & 116 & 101 \\
\hline
\end{tabular}

Several interesting observations can be made from these path plots. First, looking at the horizontal plots, the first particle shown (Figure 7.6(a)) has a portion of its path within the bend of the modeled reach for the Behaviour 3 case. The particle begins upstream of the bend, passes through the bend close to the inside edge and goes at least $10 \mathrm{~m}$ downstream of the bend before leaving the stream at the bed. In contrast, a particle (not plotted) initiated within the pool on the outside of the bend (Location 10 in Figure 7.3) followed the velocity circulation pattern within the pool as it travels upwards and drifts back to the bed. This could be an indication that particles initiated upstream of the bend are funneled through the bend towards the inside rather than settling within the pool if they don't have sufficient downward motion as also seen in the first test.

Second, looking now at the vertical path plots, these plots show areas where the vertical position of the particle path appears to be influenced by the vertical velocity of the water. The most obvious example is seen in Figure 7.6(b) as a large increase in vertical distance within the downward drifting portion of the Behaviour 3 case. In this case, the upward motion occurs as the particle is leaving the bend pool. It may be that the particle is maintaining its downward motion with respect to the bed level. However, it does indicate that the vertical velocities within the Bere Stream can influence the vertical position of particles given the range of behaviours simulated.

Finally, examining Figure 7.7(a), we see even the Behaviour 1 and 2 paths travel approximately $5 \mathrm{~m}$. This is higher than other particles examined, that begin at other locations. The particle begins at Location 2 (Figure 11.3), which is on a ridge at the exit of the bend pool. This can be seen in the initial vertical level of $9.5 \mathrm{~m}$ as compared with $9.05 \mathrm{~m}$ at Location 1 . Therefore, when the particle enters the drift, the stream bed essentially drops away from it, allowing it to drift further even if it immediately travels downward. 
Therefore, the initial vertical location of a drifting invertebrate with respect to surrounding bed levels can influence the distance it will travel.
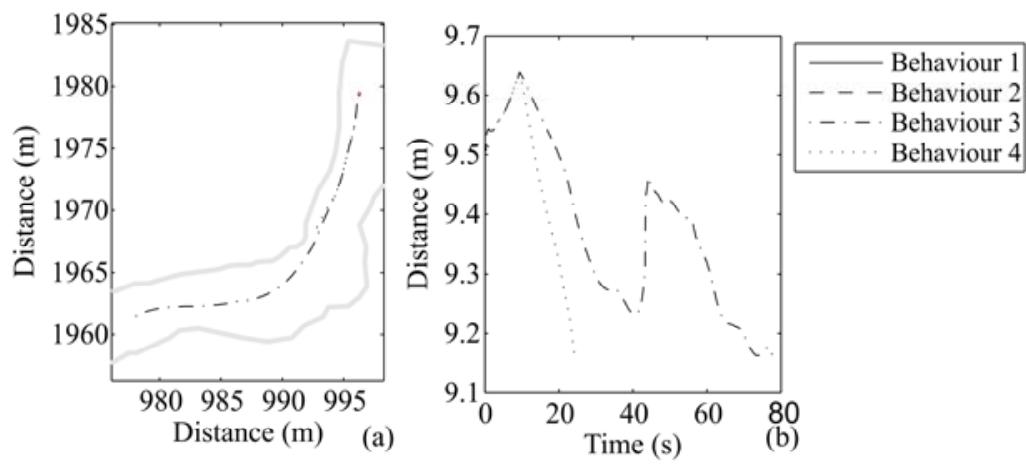

Figure 7.6 Drift paths of a $3 \mathrm{~mm}$ freshwater shrimp initiating drift at position 4 for each of four behaviours in (a) plan view and (b) in vertical direction over time. The light grey solid line represents the extents of the modeled reach.
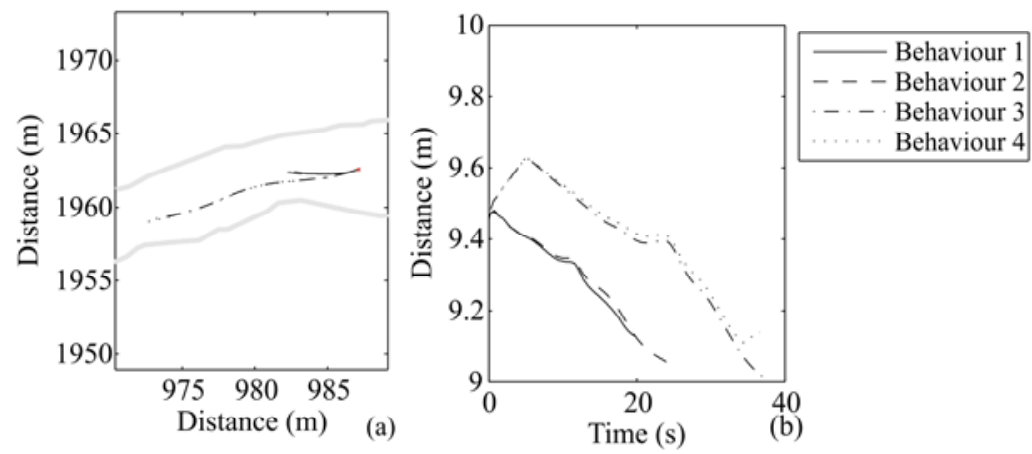

Figure 7.7 Drift paths of an $8 \mathrm{~mm}$ mayfly initiating drift at position 2 for each of four behaviours in (a) plan view and (b) in vertical direction over time. The light grey solid line represents the extents of the modeled reach. 


\subsection{Discussion and Conclusions}

The initial starting position, and the behaviour that an invertebrate displays while drifting, has been shown to impact the drift path of the invertebrate, the distance it travels and the amount of time it spends drifting. These all, in turn, have a potential impact on the amount of food available to a fish at a given location. For instance, if source areas for invertebrates are isolated to shallow areas, few, if any, prey items for drift feeding fish will pass through deep areas of bend pools. Therefore, little to no energy would be available for a fish at this location. Further, if a stream is limited to invertebrate types that display behaviours with no upward movement, in at least the initial stages of drift, very few invertebrates will be found close to the surface of the water. If engineers and planners wish to predict the impacts of their work on fish habitat using physically based bioenergetic models, taking the heterogeneity and variability of energy inputs into account could influence the absolute and relative results.

The invertebrate drift model using particle tracking has proved useful in exploring the influence of physical and behavioural factors on the amount and characteristics of the drift. It is suggested that the possibility of adding an invertebrate drift model to the bioenergetic fish habitat model (as shown schematically in Figure 7.2) would be useful for testing the sensitivity of that model to these changes in invertebrate drift (see Figure 7.8).

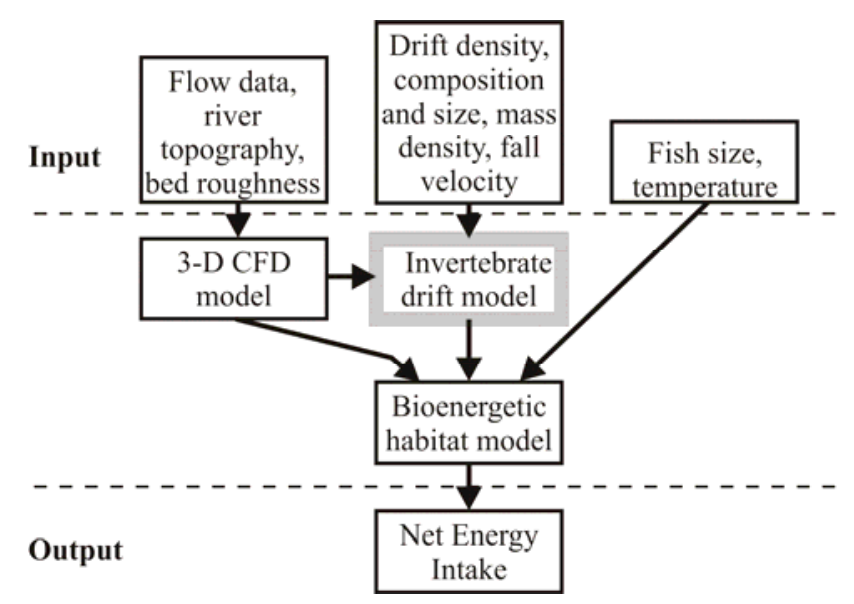

Figure 7.8 Proposed bioenergetic model schematic. 
As a physically based model, the bioenergetic fish habitat model aims to avoid the downfalls of empirically based preference models in predicting the quantity and quality of habitat available in a stream. Having an accurate portrayal of the conditions within a stream, including the variability and heterogeneity of available energy, would help engineers, hydraulic modelers and planners design stormwater management facilities, abstraction policies and stream works in ways to maximize benefits, with both human and fisheries interests in mind.

\section{References}

Addley, R. C. 1993 A mechanistic approach to modeling habitat needs of drift-feeding salmonids. Master's thesis, Utah State University, Logan, Utah.

Booker, D. J., Dunbar, M. J. \& Ibbotson, A. T. 2004 Predicting juvenile salmonid driftfeeding habitat quality using a three-dimensional hydraulic-bioenergetic model. Ecological Modelling 177 (1-2), 157-177.

Bovee, K. D., B. L. Lamb, J. M. Bartholow, C. B. Stalnaker, J. Taylor, and J. Henriksen. 1998. Streamhabitat analysis using the instream flow incremental methodology. U.S. Geological Survey,Biological Resources Division Information and Technology Report USGS/BRD-1998-0004. viii+ 131 pp.

Brittain, J. E. \& Eikeland, T. J. 1988 Invertebrate drift - A review. Hydrobiologia 166, 77-93.

Campbell, R. N. B. 1985 Comparison of the drift of live and dead Baetis nymphs in a weakening water current. Hydrobiologia 126, 229-236.

DFO. 1986. Policy for the Management of Fish Habitat. Communications Directorate, Department of Fisheries and Oceans. Ottawa

Eckman, J. E. 1990 A model of passive settlement by planktonic larvae onto bottoms of differing roughness. Limnology and Oceanography 35 (4), 887-901.

Fenoglio, S., Bo, T., Gallina, G. \& Cucco, M. 2004 Vertical distribution in the water column of drifting stream macroinvertebrates. Jounral of Freshwater Ecology 19 (3), 485-492.

Fonseca, D. M. 1999 Fluid-mediated dispersal in streams: models of settlement from the drift. Oecologia 121, 212-223.

Goodwin, A., Nestler, J. M., Loucks, D. P. \& Chapman, R. S. 2001 Simulating mobile populations in aquatic ecosystems. Journal of Water Resources Planning and Management 127 (6), 386-393.

Guensch, G.R., Hardy, T.B \& Addley, R.C. 2001. Examining feeding strategies and position choice of drift-feeding salmonids using an individual-based, mechanistic foraging model. Canadian Journal of Fisheries and Aquatic Sciences. 58(3): 446-457

Hayes, J. W. 1996 Bioenergetics model for drift-feeding brown trout. In Proceedings of the 2nd International Symposium on Hydraulic Habitats Ecohydraulics 2000 (ed. M. Leclerc, H. Capra, S. Valentin, A. Boudreault \& Y. Côté), pp. 465-476. Institute

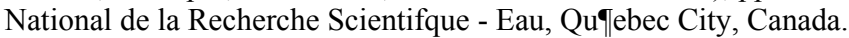


Hayes, J. W., Stark, J. D. \& Shearer, K. A. 2000 Developement and test of a wholelifetime foraging and bioenergetics growth model for drift feeding brown trout. Transactions of the American Fisheries Society 129, $315\{332$.

Hill, J. \& Grossman, G. D. 1993 An energetic model of microhabitat use for rainbow trout and rosyside dace. Ecology 74 (3), 685-698.

Hughes, N. F. \& Dill, L. M. 1990 Position choice by drift-feeding salmonids: model and test for Arctic grayling (Thymallus arcticus) in subarctic mountain streams, interior Alaska. Canadian Journal of Fisheries and Aquatic Sciences 47, 2039-2048.

Jobling, M. 1994 Fish Bioenergetics. London: Chapman and Hall.

Matter, W. J. \& Hopwood, A. J. 1980 Vertical distribution of invertebrate drift in a large river. Limnology and Oceanography 25 (6), 1117-1121.

Neale, M. 1999 An investigation of the spatial distribution of drifting invertebrates in a chalk stream. MSc/PGDip project report, Bournemouth Universtiy.

Rosenfeld, J. S., Leiter, T., Lindner, G. \& Rthman, L. 2005 Food abundance and fish density alters habitat selection, growth, and habitat suitability curves for juvenile coho salmon. Canadian Journal of Fisheries and Aquatic Sciences 62, 1691-1701.

Stalnaker, C., B. L. Lamb, J. Henriksen, K. Bovee, and J. Bartholow. 1995. The Instream Flow Incremental Methodology - A Primer for IFIM. Biological Report 29, March 1995, U.S. Department of the Interior, National Biological Service, Fort Collins, Colo.

Weber, N. 2006. Modelling Hydraulic Controls on the Spatial Distribution of Invertebrate Drift in a Natural Chalk Stream. PhD thesis, Imperial College London, London, UK.

Wilzbach, M. A., Cummins, K. W. \& Knapp, R. A. 1988 Toward a functional classification of stream invertebrate drift. Verh. Internat. Verein. Limnol. 23, 12441254. 
